\title{
Basolites: a type of Metal Organic Frameworks highly efficient in the one-pot synthesis of quinoxalines from $\alpha$-hydroxy ketones under aerobic conditions
}

\author{
Marina Godino-Ojer, ${ }^{[a, b]}$ Mariya Shamzhy ${ }^{[c]}$, Jiři Čejka, ${ }^{[c] *}$ Elena Pérez-Mayoral[ ${ }^{[a] *}$
}

Dedication ((optional))

\begin{abstract}
We report here efficient synthesis of quinoxalines from ophenylendiamine and $\alpha$-hydroxy ketones over commercial Basolites. The concentration and type of acid centres, as CUS sites, together with the porosity of the samples strongly influence the resulting conversion and selectivity. Our results indicate a new reaction route in which tautomerization reactions are also involved.
\end{abstract}

Metal Organic Frameworks (MOFs) are 3D nanoporous crystalline organic-inorganic hybrid materials constructed using multidentate organic ligands coordinated to metal ions with potential application in gas storage, sensing, drug delivery and catalysis, among others [1-2]. MOFs have been extensively investigated as catalysts in a great variety of organic transformations, including $\mathrm{C}-\mathrm{C}$ coupling, acid-base and redox reactions, even operating in water medium [3], photochemical and chemical transformations of $\mathrm{CO}_{2}$ [4], $\mathrm{H}_{2}$ production [5] but also in synergistic catalysis and tandem reactions acting as multifunctional catalysts [6]. High BET areas and pore volumes together with higher concentrations of active sites precisely located, although showing lower thermal and chemical stability in comparison with other porous catalysts, make them promising candidates for catalytic uses in liquids phase reactions [7]. MOFs are optimal catalysts to produce fine chemicals [8], particularly, for aldol-based reactions [9]. In this context, we reported $\mathrm{Cu}_{3}(\mathrm{BTC})_{2}$ as highly efficient MOF for the synthesis of quinolines via Friedländer reaction [10-13].

Basolites are commercially available MOFs widely explored in catalytic reactions. Basolites have been recently applied to the oxidation of silane [14], silylation of alcohols [15] hydrogenation of acetophenone by silanes [16] oxidative hydroxylation of arylboronic acids [17] for oxidative cyclization of methylenebisnaphthols and tandem synthesis of quinazolin$4(3 H)$-ones [18] and in the synthesis of 2,2dimethylbenzopyrane derivatives [19].

To continue our ongoing development of new porous catalytic systems active in the synthesis of heterocyclic compounds, this

[a] Dr. M. Godino-Ojer, Dr. E. Pérez Mayoral

Departamento de Química Inorgánica y Química Técnica, Universidad Nacional de Educación a Distancia, UNED, Paseo Senda del Rey 9, Facultad de Ciencias, 28040-Madrid (Spain) E-mail: eperez@ccia.uned.es

[b] Dr. M. Godino-Ojer

Facultad de Ciencias Experimentales, Universidad Francisco de Vitoria, UFV, Ctra. Pozuelo-Majadahonda km 1.800, 28223, Pozuelo de Alarcón (Madrid, Spain)

[c] Dr. Mariya Shamzhy, Prof. Jirì Čejka Department of Physical and Macromolecular Chemistry, Faculty of Science, Charles University, Hlavova 8, Prague 2 (Czech Republic) Supporting information for this article is given via a link at the end of the document.((Please delete this text if not appropriate)) paper addresses catalytic potential of commercial Basolites, particularly C300, F300 and Z1200, in the synthesis of quinoxaline derivatives, an important class of biological active compounds showing antimicrobial, antidiabetic, antiproliferative, antiglaucoma and also anticancer activity [20]. In this work, we synthesize different quinoxalines from $o$-phenylendiamine and $\alpha$ hydroxy ketones providing significant mechanistic insights when the reaction is catalyzed by Basolites. Different sets of heterogeneous catalysts have been proposed for this transformation including manganese oxide octahedral molecular sieves [21], 12-molybdophosphoric acid (MPA) [22], $\mathrm{CuCl}_{2}$ combined with molecular sieve 4A [23], ruthenium immobilized on charcoal [24], sophisticated gold-carbon nanotube nanohybrid requiring the use of basic additives [25] and $\mathrm{Cu}(\mathrm{BDC})$ [26], this last MOF being more active than zeolites.

The structural identity and phase purity of C-300, F-300 and Z1200 was confirmed using XRD (not shown here). Porosity is one of the key parameters when considering the application of MOFs in catalysis. Figure 1 shows the $\mathrm{N}_{2}$ adsorption/desorption isotherms of Basolites under investigation. All isotherms belong to type I characteristic of microporous materials. The presence of a hysteresis loop at $p>0.8$ in the isotherm of C-300 is connected with an interparticle adsorption. Pore size distributions in Figure 2 indicate that C-300 contains only the micropore less than $1 \mathrm{~nm}$, while F-300 and Z-1200 possess 2 types of micropores - the smaller pores of $1.22 \mathrm{~nm}$ diameter, and larger ones with diameter of 1.97 and $1.57 \mathrm{~nm}$ for F-300 and Z-1200, respectively. Experimental PSD curves agree with the structural features of respective Basolites. C-300 possesses a rigid framework composed of $\mathrm{Cu}_{2}$-clusters coordinated via carboxylate groups of benzene-1,3,5-tricarboxylate (BTC) to form a paddle-wheel units assembled into three-dimensional porous cubic network. C-300 possesses 3D channel system with main pores of ca. $0.9 \mathrm{~nm}$ in diameter and side pockets of ca. $0.35 \mathrm{~nm}$ in diameter [27]. In contrast to C-300, crystal structure of $\mathrm{F}-300$ constituted of $\mathrm{Fe}^{3+}$ ions and BTC linkers is unsolved due to its poor crystallinity. On the other side, 2methylimidazolate ions are associated with tetrahedrally coordinated $\mathrm{Zn}^{2+}$ ions forming a sodalite-type structure of Z1200. Z-1200 possesses large pores (1.16 nm in diameter) connected through smaller aperture of $0.34 \mathrm{~nm}$ in diameter [28]. Bimodal PSD of semi-amorphous F-300 showing the presence of larger pores was explained by existence of some cavities with a diameter being very close to the limit between micropore and mesopore [29].

Textural properties of all catalysts are summarized in Table 1. The BET areas of the C-300 and F-300 Basolites (572 and 637 $\mathrm{m}^{2} / \mathrm{g}$, Table 1) were lower than those indicated by the supplier $\left(1500-2100\right.$ and $1300-1600 \mathrm{~m}^{2} / \mathrm{g}$ for C-300 and F-300, respectively) but very close to previously reported results 
$[30,31]$. The BET area $\left(1580 \mathrm{~m}^{2} / \mathrm{g}\right)$ and micropore volume $(0.64$ $\mathrm{cm}^{3} / \mathrm{g}$ ) values of Z-1200 fit well with the predictions based on its single crystal structure [32]. The textural characteristics of Z1200 apparently surpass the values found for F-300 and C-300.

Table 1. Texture properties of samples under investigation.

\begin{tabular}{lcccc}
\hline Sample & $\begin{array}{c}\mathbf{B E T}^{\mathbf{a}} \\
\left(\mathbf{m}^{\mathbf{2}} \mathbf{g}\right)\end{array}$ & $\begin{array}{c}\mathbf{V}_{\mathbf{M l}^{\mathbf{b}}} \\
\left(\mathbf{c m}^{\mathbf{3}} / \mathbf{g}\right)\end{array}$ & $\begin{array}{c}\mathbf{V}_{\text {TOT }^{\mathbf{c}}} \\
\left(\mathbf{c m}^{3} \mathbf{g}\right)\end{array}$ & $\begin{array}{c}\mathbf{D}_{\mathbf{M}} \mathbf{l}^{\mathbf{d}} \\
(\mathbf{n m})\end{array}$ \\
\hline BASOLITE C300 & 572 & 0.24 & 0.45 & 0.89 \\
BASOLITE F300 & 637 & 0.26 & 0.30 & $1.22,1.96$ \\
BASOLITE Z1200 & 1580 & 0.64 & 0.68 & $1.23,1.57$ \\
\hline
\end{tabular}

[a] BET area (BET method, $\left.\mathrm{p} / \mathrm{p}_{0}=0.02-0.15\right)$. [b] Micropore volume (DFT, $\mathrm{N}_{2}$ on oxide surfaces, cylindrical pores). [c] Total pore volume at $\mathrm{p} / \mathrm{p}_{0}=0.99$. [d] Average pore diameter (DFT, $\mathrm{N}_{2}$ on oxide surfaces, cylindrical pores)

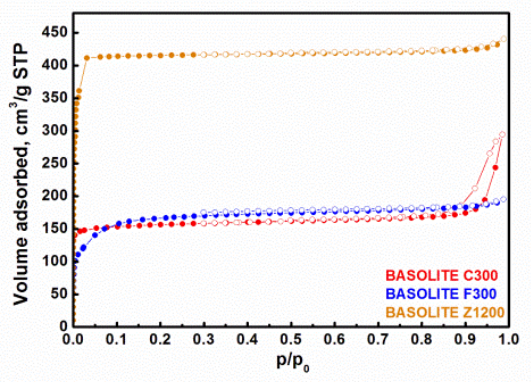

Fiaure 1. Araon adsorption (•) / desorption (o) isotherms.

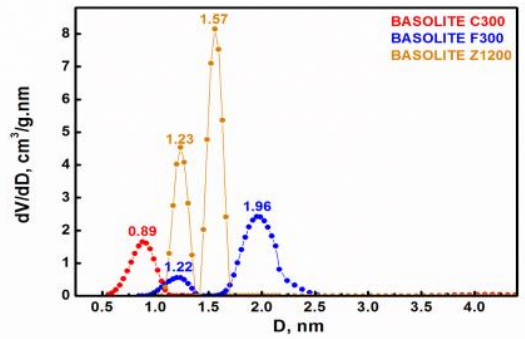

Figure 2. Pore-size distribution calculated by DFT method

The acidity of the Basolite samples was investigated by FTIR of adsorbed $d_{3}$-acetonitrile (ACN). The IR spectra of activated MOF samples before and after ACN adsorption are shown in Figures 3-5. The spectra of activated C-300 and F-300 samples show a plenty of absorption bands below $1300 \mathrm{~cm}^{-1}$ assigned to the vibrations of the BTC ligand, while the peaks in the range 1300 $1700 \mathrm{~cm}^{-1}$ are related to the carboxylate groups indicating the coordination of BTC to the metal sites [33]. Adsorption of ACN in C-300 (Figure 3) and F-300 (Figure 4) samples gave rise to the bands centered at ca. $2315-2289 \mathrm{~cm}^{-1}$ assigned to $v(\mathrm{C} \equiv \mathrm{N})$ mode characteristic of the strength of interaction of $\mathrm{ACN}$ with coordinatively unsaturated sites (CUS) of MOFs. A higher frequency of $v(\mathrm{C} \equiv \mathrm{N})$ in $\mathrm{C}-300\left(2313 \mathrm{~cm}^{-1}\right)$ vs. F-300 $(2299 \mathrm{~cm}$ $\left.{ }^{1}\right)$ reveals the higher strength of ACN interaction with CUS sites in C-300. For quantification of the concentrations of Lewis acid sites in C-300 and F-300, ACN was introduced in calibrated aliquots at room temperature to measure the $v(\mathrm{C} \equiv \mathrm{N})$ molar extinction coefficient. The gradual adsorption of $\mathrm{ACN}$ resulted in a linear increase in the intensity of $v(\mathrm{C} \equiv \mathrm{N})$ band with a slope giving $\varepsilon=2.22 \mathrm{~cm} / \mathrm{mmol}$. The concentration of CUS sites in C300 and F-300 were found to be 0.8 and $0.5 \mathrm{mmol} / \mathrm{g}$, respectively.

FTIR spectrum of Z-1200 Basolite shows characteristic absorption bands of vibrations of imidazole unit [34]. The bands in the spectral region of $900-1350 \mathrm{~cm}^{-1}$ and $1350-1500 \mathrm{~cm}^{-1}$ can be assigned to the in-plane ring bending and entire ring stretching vibrations, respectively. The absorption band at 1584 $\mathrm{cm}^{-1}$ can be specifically attributed to $\mathrm{C}=\mathrm{N}$ stretching vibrations. In addition to the framework bands, peaks at $2400-2000 \mathrm{~cm}^{-1}$ were observed in the spectrum of $Z-1200$ activated at $150{ }^{\circ} \mathrm{C}$, despite low intensities relative to the others. Vibrations of Z-1200 in 2200-2400 $\mathrm{cm}^{-1}$ region hide the characteristic $v(\mathrm{C} \equiv \mathrm{N})$ bands (Figure 5), impeding assessment of the strength and concentration of acid sites.

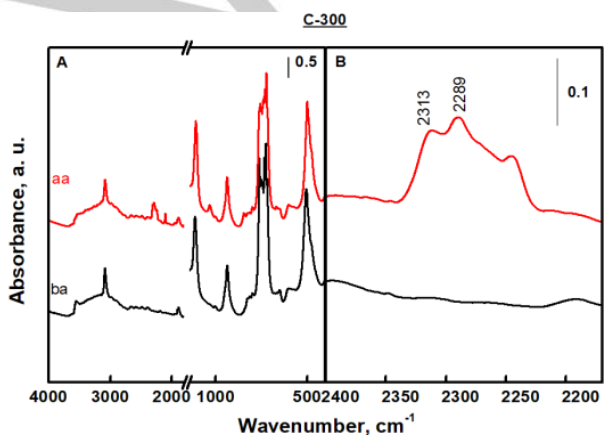

Figure 3. IR spectra of C-300 before (black spectrum) and after adsorption (red spectrum) of $\mathrm{d}_{3}-\mathrm{ACN}$ : (A) Mid-IR region; (B) region of characteristic $v(\mathrm{C}$ $\equiv \mathrm{N})$ vibrations.

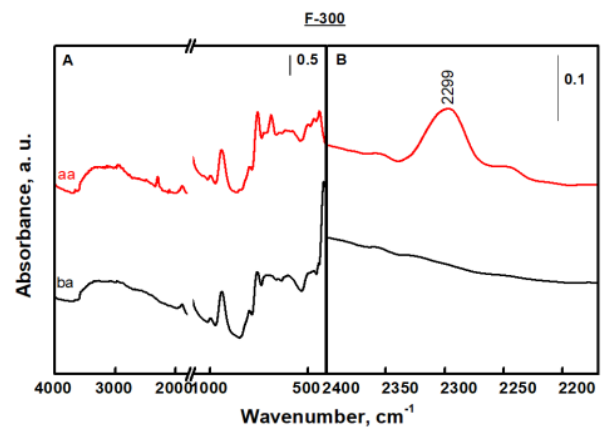

Figure 4. IR spectra of F-300 before (black spectrum) and after adsorption (red spectrum) of $\mathrm{d}_{3}-\mathrm{ACN}$ : (A) Mid-IR region; (B) region of characteristic $v(\mathrm{C}$ $\equiv \mathrm{N}$ ) vibrations.

The investigated MOFs were tested in the reaction between o-phenylendiamine $\mathbf{1}$ and benzoin $\mathbf{2 a}$, in toluene, at $100{ }^{\circ} \mathrm{C}$ (Scheme 1). 


$$
\begin{aligned}
& \begin{array}{l}
\text { 2a: } \mathrm{R}^{1}=\mathrm{R}^{2}=\mathrm{Ph} \\
\mathbf{2 b}: \mathrm{R}^{1}=\mathrm{Ph} ; \mathrm{R}^{2}=\mathrm{H} \\
2 \mathbf{2 c}: \mathrm{R}^{1}=\mathrm{R}^{2}=\mathrm{Me}
\end{array} \\
& 1 \text { Bosolite }
\end{aligned}
$$

Scheme 1. Synthesis of quinoxalines from o-phenylendiamine 1 and $\alpha$ hydroxy ketones 2 , in toluene, at $100{ }^{\circ} \mathrm{C}$.

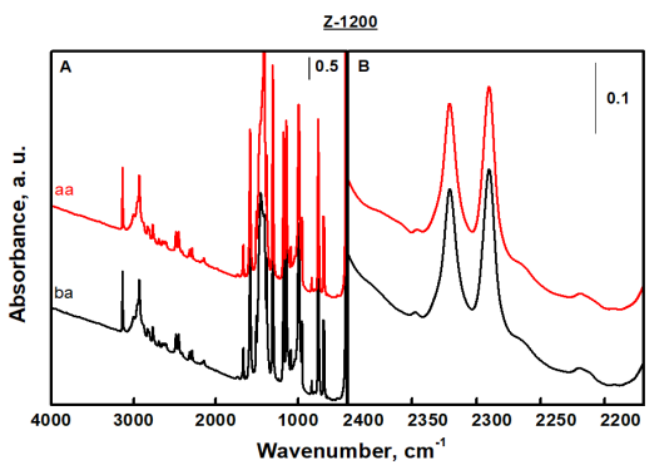

Figure 5. IR spectra of Z-1200 before (black spectrum) and after adsorption (red spectrum) of $\mathrm{d}_{3}$-acetonitrile: $(\mathrm{A})$ Mid-IR region; $(\mathrm{B})$ region of characteristic $v(\mathrm{C} \equiv \mathrm{N})$ vibrations.

Some of the catalysts reported for this synthesis promote firstly the oxidation of the corresponding hydroxy ketone providing the benzyl derivative followed by condensation with the diamine. In this context, we firstly check the catalytic performance of the Basolites in the oxidation reaction of benzoin 2a under the same experimental conditions (Scheme 2 and Figure 6).

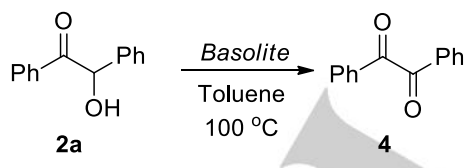

Scheme 2. Oxidation of benzoin $\mathbf{2 a}$ to benzyl $\mathbf{4}$ catalyzed by C-300, F-300 and Z-1200 Basolites under aerobic conditions.

onon-catalyzed $\quad \mathrm{C}-300 \quad \mathrm{~F}-300 \quad \mathrm{Z}-1200$

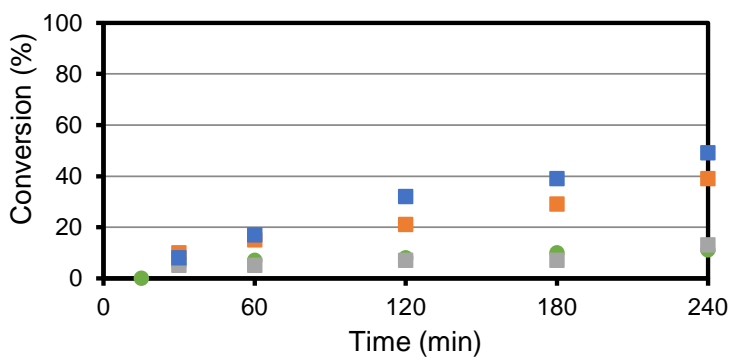

Figure 6. Oxidation of benzoin $2 a$ to benzyl 4 catalyzed by C-300, F-300 and $\mathrm{Z}-1200$ Basolites, in toluene, at $100^{\circ} \mathrm{C}$, under aerobic conditions.
While Z-1200 and F-300 promote the selective benzoin oxidation although in low yields, 50 and $40 \%$ respectively, after $4 \mathrm{~h}$ of the reaction time, C-300 barely catalyzed the reaction, the results being comparable to those obtained for the uncatalyzed process. In this regard, Cu-BTC and Fe-BTC have been recently reported in the oxidation of benzyl alcohol, in air flow using DMF as solvent, at $95^{\circ} \mathrm{C}$, yielding benzaldehyde with lower conversions values (Cu-BTC > Fe-BTC) but excellent selectivity (up to $99 \%$ ) [35]. In our case, the obtained results could be as consequence of the texture and porosity of the samples. All the explored Basolites are microporous samples, however they showed significant differences. C-300 showed the lower $\mathrm{S}_{\mathrm{BET}}, \mathrm{V}_{\mathrm{MI}}$ and $D_{\text {MI }}$ (Table 1). These parameters increase from C-300 to Z-1200 and correlate with the reactivity order (Figure 6). Visualizing the pore size distribution of Basolites (Figure 2), the larger BET area and $V_{M I}$ in Z-1200 and $F-300$ could be the reason of the observed oxidation activity of bulky alcohols such as benzoin. It is important to stress that $\mathrm{C}-300$ showed notably higher concentration of CUS than F-300, 0.8 vs. $0.5 \mathrm{mmol} / \mathrm{g}$ respectively, although it does not seem to influence the catalytic performance.

On the other side, all the investigated Basolites efficiently catalyzed the reaction between diamine $\mathbf{1}$ and benzyl $\mathbf{4}$ affording the corresponding quinoxaline $\mathbf{3 a}$ with excellent yields (up to $88 \%$ ) in only $15 \mathrm{~min}$ of the reaction time, even at room temperature, and using superior reactant amounts, observing the formation of the cyclic intermediate compound although in very low yields (4-12\%) (Scheme 3).

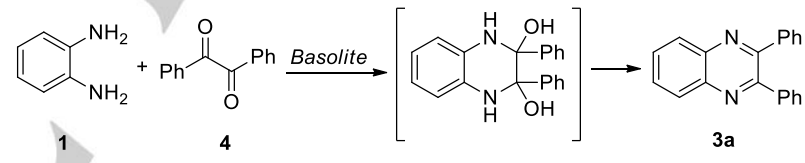

Scheme 3. Synthesis of quinoxaline 3a from o-phenylendiamine 1 and benzy 4 catalyzed by basolites.

Having these results in mind, we carried out the reaction between o-phenylenediamine 1 and benzoin $2 \mathrm{a}$ in the presence of C-300, F-300 and Z-1200 catalysts under the same experimental conditions (toluene, $100^{\circ} \mathrm{C}$ ) (Scheme 1). If the reaction between $\mathbf{1}$ and $\mathbf{2 a}$ would occur through the common sequence: i) benzoin oxidation, ii) heterocyclization and iii) dehydration, the rate limiting step would be the first step consisting of the oxidation of benzoin $2 a$ to benzyl 4 . Figure 7 depicts the conversions of $\mathbf{1}$ vs time in the synthesis of quinoxaline $\mathbf{3 a}$ from benzoin $\mathbf{2} \mathbf{a}$ in the presence of the Basolites of our choice. All the samples led to higher conversions with respect to the blank experiment establishing the reactivity order as follow: F-300 > Z-1200 > C-300. Then, the high conversion values obtained in comparison with those observed for the aerobic oxidation of benzoin 2 a make us to suspect that the reaction for the synthesis of quinoxaline $\mathbf{3} \mathbf{a}$ follows a different route. 
- non-catalyzed $\quad$ C-300 $\quad$ F-300 $\quad$ Z-1200

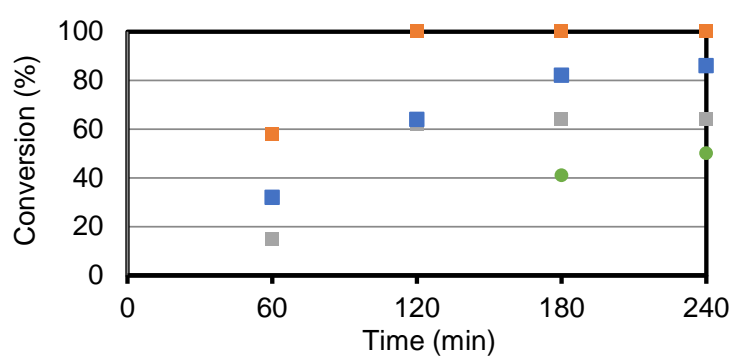

Figure 7. Conversions of $\mathbf{1}$ vs time in the synthesis of quinoxaline $\mathbf{3 a}$ from ophenylendiamine $\mathbf{1}$ and $\alpha$-hydroxy ketone $2 \mathbf{a}$, in toluene at $100{ }^{\circ} \mathrm{C}$, in the presence of Basolites C-300, F-300 and Z-1200.

Figure 8 related to the selectivity to quinoxaline $\mathbf{3 a}$ confirms that though the conversions of $\mathbf{1}$ in the absence of any catalyst are in a range of $40-50 \%$, after 3 and $4 \mathrm{~h}$ of reaction time, the selectivity to 3a was considerable lower, inferior to 20 and $40 \%$, respectively (Figure 8 ). As it can be observed from Figure 8 the use of Basolites catalyzing this reaction notably increased the selectivity to $\mathbf{3 a}$. C-300, the less active sample, surprisingly resulted in the most selective catalyst affording quinoxaline $3 a$ with total selectivity. The analysis of the ${ }^{1} \mathrm{H}$ NMR spectra of the reaction crudes showed significant differences, which could contribute to clarify the reaction mechanism. While the reaction in the absence of any catalyst yielded a mixture of quinoxaline $\mathbf{3} \mathbf{a}$ and the corresponding intermediate compound $\mathbf{A}$ (Scheme 4) [36], when using F-300 or Z-1200 catalysts, the formation of additional intermediates was observed. The presence of proton signals in the aromatic region at $8.2 \mathrm{ppm}$, almost overlapping the corresponding signals of aromatic protons in quinoxaline skeleton together the absence of aliphatic protons signals strongly suggests the formation of the intermediate B (Scheme 2) as indicated by MS experiments. Interestingly, the reaction in the presence of F-300 yielded traces of other additional intermediate which could be assigned to $\mathbf{D}$ due to the presence of symmetrical signals centered at $6.5 \mathrm{ppm}$.

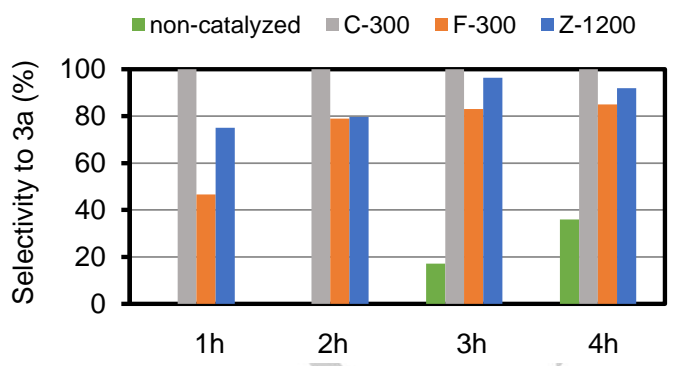

Figure 8. Selectivity to $\mathbf{3} \mathbf{a}$ in the synthesis of quinoxalines from 0 phenylendiamine $\mathbf{1}$ and $\alpha$-hydroxy ketone $\mathbf{2 a}$, in toluene at $100{ }^{\circ} \mathrm{C}$, in the presence of basolites.

Scheme 4 shows also the other accepted mechanism reported for the investigated reaction consisting of the cascade reactions condensation-dehydration-cyclization and aromatization (Scheme 4, Path a) [37]. Our results then open the doors to consider other alternative reaction pathway for the formation of quinoxaline 1a in the presence of Basolites probably following the Path $b$.

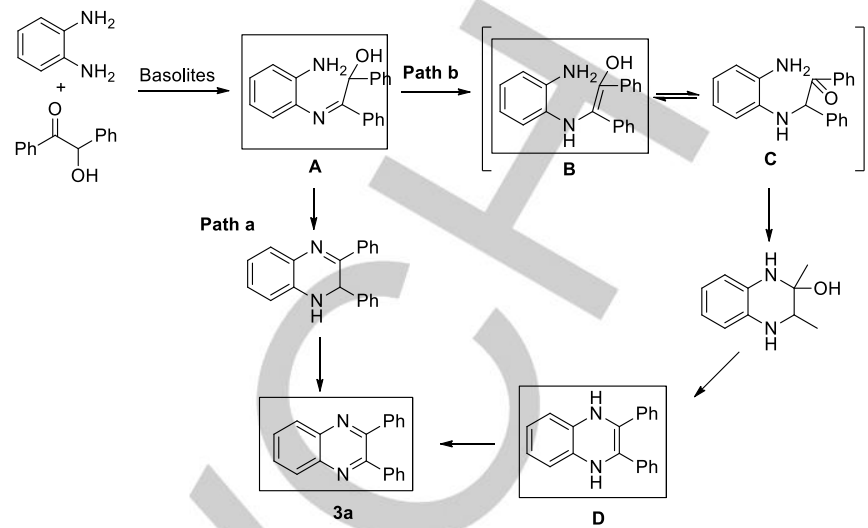

Scheme 4. Reaction mechanism for the synthesis of quinoxalines from 0 phenylendiamine $\mathbf{1}$ and $\alpha$-hydroxy ketones 2 , in toluene at $100{ }^{\circ} \mathrm{C}$, in the presence of Basolites F-300 and Z-1200.

Considering these results, we can conclude that the synthesis of quinoxaline 3a catalyzed by Basolites under study takes place through the cascade reactions preferentially following the imination, tautomerization, heterocyclization, dehydration and dehydrogenation reactions sequence, although the competitive pathway consisting of the benzoine oxidation-heterocyclizationdouble dehydration cannot be neglected. The observed reactivity depends on the concentration and nature of the acid sites on Basolites. Thus, the presence of higher concentration of Lewis acid sites in C-300 (0.8 mmol/g) yielded to quinoxaline 3a in approximately $60 \%$ with total selectivity. In this case, the maintained yield with the time could be due to the strong interactions of quinoxaline with CUS sites through its $\mathrm{N}$ atoms. The absence of any intermediate compound when using C-300 confirms the hard Lewis acid character and high dehydrogenation capability compared to F-300 and Z-1200 catalysts. The selectivity order approximately at $60 \%$ of conversion is as follow: C-300 > Z-1200 > F-300 (Figures 7 and 8). Textural parameters of the samples could also influence the catalytic performance in terms of conversion. F-300 and Z-1200 presenting the highest $\mathrm{BET}$ areas, micropore volumes and pore diammeters gave increased conversion values of $\mathbf{1}$. We also investigated the reaction in the presence of different catalyst amounts over F-300 (Figure 9). It is noticeable that using lower catalyst amounts the conversion of 1 was $100 \%$, after $2 \mathrm{~h}$ of reaction time, selectivity to quinoxaline $\mathbf{3 a}$ increasing with the amount of the catalyst as expected. However, while the reaction in the presence of the highest amount of $\mathrm{F}-300$ yielded a mixture of quinoxaline $3 \mathbf{a}$ and $\mathbf{B}$ in $79 \%$ and $21 \%$, respectively, when using inferior catalyst amount it was observed the formation of quinoxaline $\mathbf{3} \mathbf{a}$ and the acyclic intermediate $\mathbf{A}$ (Scheme 3 ). Then selectivity differences seem to be related with the concentration of the catalytic acid sites than the porosity of the samples.

We also explore the reaction for other carbonyl compounds $\mathbf{2 b}$ and $\mathbf{2 c}$ in the presence of F-300 catalyst. Thus, the reaction of diamine $\mathbf{1}$ and $\mathbf{2 b}$ gave quinoxaline $\mathbf{3 b}$ in $71 \%$ of yield after $2 \mathrm{~h}$ of reaction time as unique reaction product. When using acetoin $2 \mathrm{c}$ high conversion values of 1 were obtained ( $86 \%$ after $3 \mathrm{~h}$ ) but considerable decreased selectivity to $\mathbf{3 c}$. In this case, the 
formation of intermediate compounds $\mathbf{A}$ and $\mathbf{D}$ in 1:1 ratio was observed. The diminished selectivity is probably related to the steric effects by the presence of methyl groups.

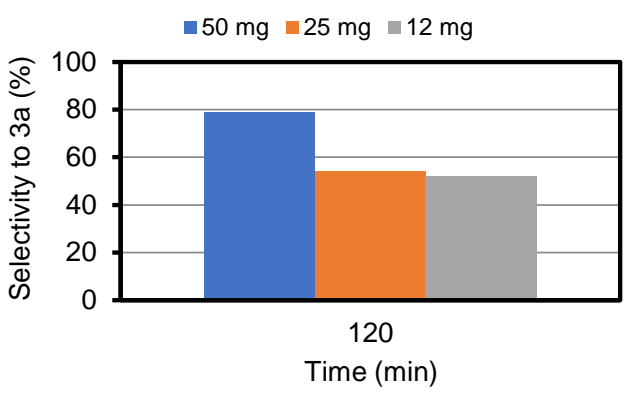

Figure 9. Synthesis of quinoxaline 3a from o-phenylendiamine 1 and $\alpha$ hydroxy ketone $2 \mathrm{a}$, in toluene at $100{ }^{\circ} \mathrm{C}$, catalyzed by F-300. Influence of the catalyst amount.

In summary, we report herein commercial available Basolites as efficient catalysts for one-pot synthesis of quinoxalines from ahydroxy ketones. The acid character in combination with the dehydrogenation capability and perhaps porosity of the samples seem to control the observed reactivity. Our results strongly suggest a new operative pathway for the transformation under study following imination, tautomerization, heterocyclization, dehydration and dehydrogenation reactions sequence.

\section{Experimental Section}

\section{Characterization of the Basolites}

The phase purity of the catalyst was confirmed by X-ray powder diffraction (XRD) using a Bruker AXSD8 Advance diffractometer with a graphite monochromator, a position sensitive detector (Våntec-1) and CuKa $(\lambda=1.54184 \AA)$ radiation in Bragg-Brentano geometry at a scan rate of $0.25^{\circ}(2 \theta) \mathrm{min}^{-1}$.

Adsorption isotherms of nitrogen at $-196{ }^{\circ} \mathrm{C}$ (argon at $-196 /-186{ }^{\circ} \mathrm{C}$ ) were recorded using an ASAP 2020 (Micromeritics) static volumetric apparatus. Prior to sorption measurement, the sample was degassed with a turbomolecular pump at $150{ }^{\circ} \mathrm{C}$ for $6 \mathrm{~h}$. The specific surface area (BET) was evaluated by BET method [38] using adsorption data in the $\mathrm{p} / \mathrm{p}_{0}$ range of $0.05-0.20$. The volume of micropores $\left(\mathrm{V}_{\mathrm{MI}}\right)$ and microporesize distribution (DMI) were evaluated using the DFT method $\left(\mathrm{N}_{2}\right.$ adsorption on oxide surfaces with cylindrical pores).

The acidity of the samples was assessed using FTIR spectroscopy of adsorbed $d_{3}$-acetonitrile $(A C N)$. The samples were pressed into selfsupporting wafers with a density of $8.0-12 \mathrm{mg} \mathrm{cm}^{-2}$ and activated in situ at $\mathrm{T}=150^{\circ} \mathrm{C}$ and $p=5 \cdot 10^{-5}$ Torr for $6 \mathrm{~h}$. ACN adsorption was carried out at ambient temperature for $30 \mathrm{~min}$ at a partial pressure of 5 Torr, followed by desorption for $20 \mathrm{~min}$ at the same temperature. Before adsorption ACN was degassed by freezing-pump-thaw cycles. All spectra were recorded using Nicolet 6700 spectrometer equipped with MCT/B detector with a resolution of $4 \mathrm{~cm}^{-1}$ by collecting 128 scans for a single spectrum at room temperature. All the spectra were normalized to a wafer density of $10 \mathrm{mg} \mathrm{cm}^{-2}$.

\section{Catalytic performance.}

Synthesis of quinoxalines. In a typical experiment, a solution of ophenylendiamine $1(0.5 \mathrm{mmol})$ and different $\alpha$-hydroxy ketones $2(0.5$ $\mathrm{mmol})$ in toluene $(5 \mathrm{~mL})$ in a three-necked vessel, equipped with thermometer, was placed on a multiexperiment work station StarFish (Rad ${ }^{*}$ ley's Discovery Technologies IUK). When the temperature reaches $100{ }^{\circ} \mathrm{C}$, the corresponding basolite was added $(50 \mathrm{mg})$ and the reaction mixture was maintained during the appropriated time. The samples were periodically taken at $15,30,60,120,180$ and $240 \mathrm{~min}$, diluted with dichloromethane $(0.5 \mathrm{~mL})$, and the catalyst was filtered off and the solvent evaporated in vacuo.

Synthesis of benzyl. The synthesis of the benzyl derived from benzoine 2a was carried out by using the same experimental protocol mentioned above for the synthesis of quinoxalines, under aerobic conditions, but in absence of $o$-phenylendiamine.

The reaction was followed by TLC chromatography performed on DCAulofolien/Kieselgel $60 \mathrm{~F}_{245}$ (Merk) using mixtures of $\mathrm{CH}_{2} \mathrm{Cl}_{2} / \mathrm{EtOH}$ 98:2 as eluent. Reaction products were characterized by ${ }^{1} \mathrm{H}$ NMR spectroscopy. NMR spectra were recorded by using a Bruker AVANCE DPX-300 spectrometer $\left(300 \mathrm{MHz}\right.$ for $\left.{ }^{1} \mathrm{H}\right) .{ }^{1} \mathrm{H}$ chemical shifts in $\left[\mathrm{d}_{6}\right] \mathrm{DMSO}$ are referenced to internal tetramethylsilane.

\section{Acknowledgements}

This work has been supported in part by Spanish Ministry (project CTM2014-56668-R). J.Č. acknowledges the support of the Czech Science Foundation for the project EXPRO (1927551X).

Keywords: Basolites - Metal-Organic-Frameworks• Nanocatalysts • Fine Chemicals • Quinoxalines

[1] D. Farrusseng, S. Aguado, C. Pinel, Angew. Chem. Int. Ed. 2009, 48, 7502-7513.

[2] M. Almáši, V. Zeleňák, M. Opanasenko, J. Čejka, Dalton Trans, 2014 43, 3730-3738.

[3] A. Dhakshinamoorthy, A. M. Asiric, H. Garcia, Chem. Commun. 2014 50, 12800-12814.

[4] H. He, J. A. Perman, G. Zhu, S. Ma, Small 2016, 12, 6309-6324.

[5] A. Rossin, G. Tuci, L. Luconi, G. Giambastiani, ACS Catal. 2017, 7, 5035-5045.

[6] a) Y.-B. Huang, J. Liang, X.-S. Wang, R. Cao, Chem. Soc. Rev. 2017 46, 126-157. b) M. Opanasenko. Catal. Today 2015, 243, 2-9.

[7] J. Liang, Z. Liang, R. Zou, Y. Zhao, Adv. Mater. 2017, 1701139.

[8] a) N. Pal, A. Bhaumik, RSC Adv. 2015, 5, 24363-2439; b). A. Dhakshinamoorthy, M. Opanasenko, J. Cejka, H. Garcia, Catal. Sci. Technol. 2013, 3, 2509-2540.

[9] A. Dhakshinamoorthy, M. Opanasenko, J. Cejka, H. Garcia, Adv. Synth Catal. 2013, 355, 247-268.

[10] E. Pérez-Mayoral, J. Cejka, ChemCatChem 2011, 3, 157-159.

[11] E. Pérez-Mayoral, Z. Musilová, B. Gil, B. Marszalek, M. Polozij, P. Nachtigall, J. Cejka, Dalton Trans. 2012, 41, 4036-4044.

[12] M. Polozij, E. Pérez-Mayoral, J. Cejka, J. Hermann, P. Nachtigall, Catal. Today 2013, 204, 101-107.

[13] M. Godino-Ojer, A. J. López-Peinado, F. J. Maldonado-Hódar, and E. Pérez-Mayoral, ChemCatChem 2017, 9, 1422-1428.

[14] N. Anbu, A. Dhakshinamoorthy, Appl. Catal. A 2017, 544, 145-153.

[15] A. Dhakshinamoorthy, A. Santiago-Portillo, P. Concepcion, J. R. Herance, S. Navalon, M. Alvaro, H. Garcia, Catal. Sci. Technol. 2017, 7, 2445-2449. 
[16] A. Dhakshinamoorthy, M. Alvaro, H. Garcia, Catal. Commun. 2017, 97, 74-78.

[17] A. Dhakshinamoorthy, A. M. Asiri, H. Garcia, Tetrahedron 2016, 72 2895-2899.

[18] A. R. Oveisi, A. Khorramabadi-zad, S. Daliran, RSC Adv. 2016, 6, 1136-1142.

[19] M. V. Shamzhy, M. V. Opanasenko, H. Garcia, J. Cejka, Micropor. Mesopor. Mat. 2015, 202, 297-302.

[20] P. S. Jadhavar, D. Kumar, P. Purohit, B. V. Pipaliya, In: Green Chemistry: Synthesis of Bioactive Heterocycles, A. Kumar, S. Bhagat, A. K. Chakraborti, K. L. Ameta, A. Dandia (eds.), Springer 2014

[21] S. Sithambaram, Y. Ding, W.Li, X. Shen, F. Gaenzler, S. L. Sui, Green Chem. 2008, 10, 1029-1032.

[22] K. T. Venkateswara Rao, P. S. Sai Prasad, N. Lingaiah, J. Mol. Catal. A: Chem. 2009, 312, 65-69.

[23] C. S. Cho, W. X. Ren, J. Organomet. Chem. 2009, 694, 3215-3217.

[24] A.V. Kumar, V.P. Reddy, K.R. Rao, Synlett 2010, 17, 2571-2574.

[25] N. Shah, E. Gravel, D. V. Jawale, E. Doris, I. N. N. Namboothiri, ChemCatChem 2015, 7, 57-61.

[26] G. H. Dang, Y. T. H. Vu, Q. A. Dong, D. T. Le, T. Truong, N. T. S. Phan, Appl. Catal. A 2015, 491, 189-195.

[27] a) S. S. Y. Chui, S.M.F. Lo, J. P. H. Charmant, A. G. Orpen, I. D. Williams, Science 1999, 283, 1148-1150.
[28] K. S. Park, Z. Ni, A. P. Côté, J. Y. Choi, R. Huang, F. J. Uribe-Romo, H K. Chae, M. O'Keeffe, O. M. Yaghi, Proc. Natl. Acad. Sci. USA 2006 103, 10186-1019

[29] M. Sanchez-Sanchez, I. de Asua, D. Ruano, K. Diaz, Cryst. Growth Des. 2015, 15, 4498-4506.

[30] A. Dhakshinamoorthy, M. Alvaro, P. Horcajada, E. Gibson, M Vishnuvarthan, A. Vimont, J. M. Grenèche, C. Serre, M. Daturi, H. Garcia, ACS Catal. 2012, 2, 2060-2065.

[31] G. Majano, O. Ingold, M. Yulikov, G. Jeschke, J. Perez-Ramirez, CrystEngComm 2013, 15, 9885-9892.

[32] E. L. First, C. A. Floudas, Micropor. Mesopor. Mat. 2013, 165, 32-39.

[33] L. Ge, W. Zhou, V. Rudolpha, Z. Zhu, J. Mater. Chem. A 2013, 1, 6350 6358.

[34] a) E. M. Banach, H. A. Stil, H. Geerlings, J. Mater. Chem. 2012, 22, 324-327; b) Y. Hu, H. Kazemian, S. Rohani, Y. Huang, Y. Song, Chem. Commun. 2011, 47, 12694-12696.

[35] L. Penga, S. Wua, X. Yanga, Jing Hua, X. Fua, M. Lia, L. Baia, Q. Huob, J. Guan, New J. Chem. 2017, 41, 2891-2894.

[36] H. K. Kadam, S. Khan, R. A. Kunkalkar, S. G. Tilve, Tetrahedron Lett. 2013, 54, 1003-1007.

[37] M. R. Islami, Z. Hassani, Arkivoc. 2008, xv, 280-287.

[38] S. Brunauer, P. H. Emmett, E. Teller, J. Am. Chem. Soc. 1938, 60, 309-319. 
Entry for the Table of Contents (Please choose one layout)

Layout 1:

\section{COMMUNICATION}

The synthesis of quinoxalines from ophenylendiamine and $\alpha$-hydroxy ketones catalyzed by commercial Basolites is reported. The combination of the concentration and type of acid centres and the porosity of the samples strongly influence conversion and selectivity. Our results indicate a new reaction route in which tautomerization reactions are also involved.

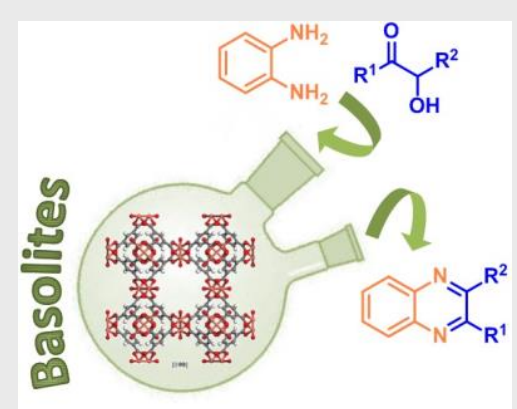

Marina Godino-Ojer, Mariya Shamzhy, Jiři Čejka, ${ }^{*}$ Elena Pérez-Mayoral ${ }^{*}$ Author(s), Corresponding Author(s)*

Page No. - Page No.

Basolites: a type of Metal Organic Frameworks highly efficient in the one-pot synthesis of quinoxalines from $\alpha$-hydroxy ketones under aerobic conditions 